\title{
A aplicação da "Lei para Inglês Ver" de 1831 para a libertação de escravos no Rio Grande do Sul
}

\author{
Cícero Augusto Richter Schneider ${ }^{1}$ \\ Roberto Radünz ${ }^{2}$ \\ Olgário Paulo Vogt
}

\section{RESUMO}

A Lei Feijó, promulgada no dia 7 de novembro de 1831, visava reprimir e dar fim ao tráfico de escravos africanos, dando, assim, uma demonstração à Coroa britânica - que fazia pressão para que o tráfico fosse abolido - de que o Brasil estava investindo para terminar o comércio negreiro internacional. No contexto dessa lei se enquadra o processo judicial de três gerações da mesma família de escravas que foram libertas. Arminda, Rafaela e Maria respectivamente neta, mãe e avó, foram alforriadas meio século após a promulgação da lei pela interpretação do juiz que considerou ilegítima a condição das pardas. Com seus senhores, Maria e Rafaela viveram parte de sua vida no Uruguai e, ao entrarem em território do Brasil, deveriam ser consideradas livres. O trabalho baseou-se, principalmente, na transcrição e análise do processo-crime da parda Arminda, proveniente do Arquivo Público do Estado do Rio Grande do Sul (APERS). A partir daí, pôde-se demonstrar a importância da Lei Feijó para a libertação de escravos que cruzavam a fronteira, entrando no Brasil.

Palavras-Chave: Escravidão. Lei Feijó. Tráfico de escravos. Re-escravização.

\begin{abstract}
The Feijó Law, promulgated in november $7^{\text {th }}, 1831$, aimed the repression and the abolition of the African slaves traffic, demonstrating to the british Crown - that make pression for the trade abolition - that Brazil was investing in order to finish the international slave trade. In the context of this law fits the judicial process of three generations of the same family of slaves that were freed. Arminda, Rafaela and Maria, respectively granddaughter, mother, and grandmother, were freed half a century after the promulgation of the law by the interpretation of the judge that considered the brownish women condition as unlawful. With their lords, Maria and Rafaela lived part of their life in Uruguai and, in the moment that they entered in Brazilian territory, should be considered free. This work was based, mainly, in the transcription and analysis of the criminal process of Arminda, proceeding from the Publico Archive of the State of Rio Grande do Sul. From there, it was possible to demonstrate the importance of the Feijó Law to the liberation of slaves that crossed the frontier, entering in Brazil.
\end{abstract}

Keywords: Slavery. Feijó Law. Slaves trade. Re-enslavement.

\footnotetext{
${ }^{1}$ Aluno do Curso de História da Universidade de Santa Cruz do Sul - UNISC.

2 Professor do Departamento de História e Geografia na Universidade de Santa Cruz do Sul e Professor na Universidade de Caxias do Sul - UCS.

${ }^{3}$ Professor do Departamento de História e Geografia da Universidade de Santa Cruz do Sul. <olgario@unisc.br>
} 


\section{INTRODUÇÃO}

O tráfico transatlântico de escravos africanos foi um importante fator econômico e cultural de diversos países, entre eles o Brasil, tendo durado quase quatro séculos. Esta atividade, contudo, ao final do século XVIII e início do XIX, na Europa, passou a ser vista de forma contrária aos ideais mais comuns, começando a ser considerada como desumana. O fim do tráfico na América teve seu início com a pressão britânica efetuada no princípio do século XIX. Neste período, ocorreram sucessos no que concerne à abolição do comércio na GrãBretanha, com a proibição deste para os súditos britânicos a partir de 1808.

A partir de então, a Grã-Bretanha passou a realizar uma ampla campanha, visando à abolição do tráfico em vários países, entre eles, o Brasil. Nesse sentido, vários tratados foram firmados no primeiro quartel do século XIX, levando à promulgação da Lei de 7 de Novembro de 1831, a Lei Feijó, que tinha como premissa e extinção do tráfico de escravos no Brasil.

Essa lei teve pouco efeito prático e ficou conhecida como "Lei para Inglês Ver", pelo menos no que se refere ao período imediato à sua promulgação. Ela foi utilizada esporadicamente por juízes logo após sua publicação e, de maneira mais sistemática, na segunda metade do século XIX, com vistas a libertar escravos que entraram à revelia da lei em solo brasileiro.

Durante a Revolução Farroupilha, em data imprecisa, o casal Simão Soares dos Santos e Firmina Soares de Freitas rumou ao Estado Oriental do Uruguai, permanecendo lá por algum tempo. Junto com eles foi a escrava Maria. Esta cativa, durante a estadia na Banda Oriental, concebeu uma filha, batizada com o nome de Rafaela. Com a ocorrência da Guerra Grande no Estado Oriental, o casal retornou ao Império entre 1839 e 1840, trazendo consigo as duas pardas. A dita Rafaela, por volta do início da década de 1860, também teve uma filha, de nome Arminda. Esta parda, no ano de 1883, envolveu-se em um processo legal em busca de sua liberdade, tendo como base a Lei de 7 de novembro de 1831. O caso acaba por abarcar, também, sua mãe Rafaela e sua avó Maria.

Esse texto visa demonstrar, a partir do processo, a utilização da Lei de 7 de novembro de 1831 na libertação de escravos que entraram no Brasil após a promulgação da legislação, tendo como recorte territorial a Província do Rio Grande de São Pedro do Sul. Com isto, pretende-se mostrar o contexto do início do século XIX, marcando o princípio do fim do tráfico negreiro transatlântico, a criação e a forma como a Lei Feijó foi aplicada e de que maneira ela beneficiou os cativos. $\mathrm{O}$ estudo parte de um caso pontual que permite ao historiador vasculhar as profundezas da estrutura escravista do Brasil imperial. 
Esse artigo enquadra-se no campo historiográfico da Micro-História, que pode ser ilustrada através de uma metáfora: "o microhistoriador examina uma gota d'água para enxergar algo do oceano inteiro.” (BARROS, 2013, p. 154-155). Segundo o mesmo, a MicroHistória é

uma redução na escala de observação do historiador com o intuito de se perceber aspectos que de outro modo passariam desapercebidos. (...) Comunidade examinada pela Micro-História pode aparecer, por exemplo, como um meio para atingir a compreensão de aspectos específicos relativos a uma sociedade mais ampla (BARROS, 2013, p. 153).

Para a realização deste estudo, foram utilizados dois documentos principais, provenientes do Arquivo Público do Estado do Rio Grande do Sul (APERS): o processocrime que relata o caso da parda Arminda (APERS: 1883 - Civil e Crime. № 1714 , E. 122, M. 55) e o inventário de Simão Soares dos Santos (APERS: 1850 - Civil e Crime. Autos $\mathrm{N}^{\circ}$ 3, M. 1 E. 122). Os processos criminais "se constituem em uma preciosa fonte documental da qual o historiador pode se valer para travar contato com culturas populares do passado" (VOGT; RADÜNZ, 2012), estando entre elas a dos escravos que aqui permaneceram. Ambas as fontes primárias foram digitalizadas (fotografadas) e, após, transcritas para fins de análise e elaboração desse artigo. Juntamente com o processo-crime e o inventário, foi analisada a legislação principal abordada no estudo (a Lei Pátria de 7 de Novembro de 1831), além de outros instrumentos legais vigentes, como o Código Criminal do Império do Brasil, de 1830. Vistas as fontes primárias e os tópicos delas derivados, foi feita uma revisão bibliográfica visando à contextualização e entendimento do caso.

\section{O PONTO DE PARTIDA}

Entre os anos de 1839 e 1840, Simão Soares dos Santos, acompanhado de sua esposa, Firmina Soares de Freitas, retornou do Estado Oriental do Uruguai à província do Rio Grande de São Pedro do Sul, migrando da mesma República Oriental em decorrência da Guerra Grande (1839-1851). Esta guerra civil opôs os blancos, comandados por Manoel Oribe, e os colorados, liderados por Fructuoso Rivera (MATHEUS, 2012), e teve influência nas diversas interpretações da questão fronteiriça entre o Império do Brasil e a República Oriental do Uruguai no que concerne à liberdade ou escravização de cativos, tanto no Brasil como no Estado Oriental.

Além dos demais familiares e serviçais, o casal trazia consigo Maria e Rafaela, ambas escravas. Rafaela, filha de Maria, havia sido concebida ainda em território da República Oriental e, por efeito da referida lei de 1831, poderia ser considerada livre. O casal, 
ao retornar ao Império, foi residir, primeiramente, em Ibicuhiy. Neste local, em data indeterminada, Simão Soares dos Santos veio a falecer. A pedido de Firmina, foi feito um inventário amigável ${ }^{4}$. Como herdeiras, foram registradas as filhas do casal, Anna Soares de Freitas e Elisia Candida Soares. Este inventário, datado de 1850, foi realizado no juízo municipal da Vila da Encruzilhada, termo que Firmina e Anna passaram a tomar como residência. No mesmo documento, dentre os bens do finado, constam seis escravos:

\section{Tabela 1: Inventário de Simão Soares dos Santos ${ }^{5}$}

\begin{tabular}{|l|l|}
\hline \multicolumn{2}{|c|}{ Escravos } \\
\hline Domingos - 60 anos & $100 \$ 000$ \\
\hline Diogo Crioulo - 35 anos & $400 \$ 000$ \\
\hline Maria - 28 anos & $300 \$ 000$ \\
\hline Rafaella - 11 anos & $300 \$ 000$ \\
\hline Eva - 9 anos & $250 \$ 000$ \\
\hline Eusebia - 3 anos & $125 \$ 000$ \\
\hline & \multicolumn{1}{|c|}{ Animais } \\
\hline 258 reses nesta província a 4000 & $1: 032 \$ 000$ \\
\hline 21 ditas no Estado Oriental a 2000 & $42 \$ 000$ \\
\hline 7 novilhos a 8000 & $56 \$ 000$ \\
\hline 19 bois mansos & $228 \$ 000$ \\
\hline 2 cavalos mansos a 10000 & $20 \$ 000$ \\
\hline 5 éguas xucras - a 2000 & $10 \$ 000$ \\
\hline 1 carreta velha & $20 \$ 000$ \\
\hline Dívida da herdeira Elisia & $32 \$ 000$ \\
\hline
\end{tabular}

Fonte: APERS: 1850 - Civil e Crime. Autos N 3 , M. 1 E. 122

A partir das informações constantes nesse inventário, Simão Soares dos Santos aparece como um pequeno proprietário de terras, que possui seis cativos. O monte mor do finado foi avaliado em dois contos e novecentos e quinze réis. Entre os cativos que são listados no documento, Maria e Rafaela ainda aparecem inclusas aos bens do casal.

Feita a partilha, a viúva Firmina ficou com metade dos bens, dentre eles os escravos Domingos, Diogo, Maria e Eusebia. A filha Elisia ficou com a posse de vários animais, além de outros bens. Finalmente, a filha Anna herdou, entre outros, as cativas Rafaela e Eva.

\footnotetext{
${ }^{4}$ Inventário Simão Soares dos Santos (APERS: 1850 - Civil e Crime. Autos No 3, M. 1 E. 122).

${ }^{5}$ Dados retirados do inventário de Simão Soares dos Santos (APERS: 1850 - Civil e Crime. Autos No 3, M. 1 E. 122).
} 


\section{O CASO DA PARDA ARMINDA}

Aos sete dias do mês de maio do ano de 1883, na Vila da Encruzilhada, teve início o processo criminal que tinha como autora a parda Arminda, através de seu curador, o advogado João Baptista de Oliveira Brandão. O caso inicia com a apresentação da denúncia, assinada pelo juiz municipal do termo da Vila da Encruzilhada, Doutor Francisco de Farias Villas Boas, que "Cumprindo com os preceitos da lei vem perante Vossa Senhoria o Promotor Público da Comarca denunciar a Feliciano Pereira Henriques, natural deste município, e morador no $1^{\circ}$ districto desta villa (...)" (APERS: 1883 - Civil e Crime. №. 1714, E. 122, M. 55.). ${ }^{6}$ Logo após, é feito um relato da vinda do casal Simão Soares dos Santos e Firmina Soares de Freitas no Estado Oriental do Uruguai, conforme relatado acima.

Arminda seria, de acordo com sua defesa sumária, filha da cativa Rafaela e, portanto, neta da escrava Maria. A cativa Rafaela ficou em posse de Anna Soares, que viúva de primeiro marido, casou-se com Feliciano Pereira Henriques. Em data indeterminada, a senhora de Rafaela faleceu, passando o domínio da cativa ao viúvo Henriques. Arminda julgava ser seu cativeiro ilegal, denunciando seu senhor, Feliciano Pereira Henriques sob os preceitos do artigo 179 do Código Penal do Império.

O artigo 179 do Código Penal (Lei de 16 de dezembro de 1830), incluído na parte terceira, intitulada "Dos crimes particulares", título I, "Dos crimes contra a liberdade individual" abordava

Art. 179. Reluzir á escravidão a pessoa livre, que se achar em posse da sua liberdade.

Penas - de prisão por tres a nove annos, e de multa correspondente á terça parte do tempo; nunca porém o tempo de prisão será menor, que o do captiveiro injusto, e mais uma terça parte. (BRASIL, 1830).

A questão criada por estas condições é: como Arminda podia ser re-escravizada? A resposta está na legislação abordada para justificar a liberdade da parda, a Lei de 7 de Novembro de 1831, a Lei Feijó.

A Lei de 1831, criada sob pressão britânica, com o intuito de dar fim ao tráfico negreiro transatlântico, dizia que, após a data de sua promulgação, todos os escravos que adentrassem em território brasileiro deveriam ser considerados livres. Contudo, apesar de válida, ela não foi cumprida de acordo com seus preceitos, não sendo utilizada como forma de abolir o tráfico de cativos. Este continuou até meados do século XIX. Porém, a lei não foi revogada. Ela passou a ser interpretada, a partir de 1860, por parcela dos operadores da justiça que visavam à liberdade de seus curatelados, neste caso, os escravos africanos que haviam

${ }^{6}$ APERS: 1883 - Civil e Crime. №. 1714, E. 122, M. 55. A partir daqui referido como APERS: 1883. 
adentrado em território imperial após a data de oficialização da legislação (ZUBARAN, 2006). A Lei Feijó passou a ser usada, também, para justificar a liberdade de escravos brasileiros que, tendo atravessado as fronteiras nacionais, principalmente com os países do Prata, voltavam a trespassar a região fronteiriça, retornando ao Império.

No caso de Arminda, a utilização da Lei de 07 de Novembro de 1831 não se aplicava apenas a ela, mas também a Maria e Rafaela, respectivamente sua avó e mãe. Na defesa da parda Arminda, é novamente relatada a ida de Simão e Firmina para o Estado Oriental do Uruguai, levando consigo a escrava Maria. Ao regressarem, entre os anos de 1839 e 1840, acompanhados de Maria e sua filha Rafaela, nascida em território estrangeiro, atravessaram a fronteira entre a República Oriental e o Império do Brasil. Sendo assim, de acordo com a Lei de 1831, Maria e Rafaela, por terem cruzado a linha fronteiriça, poderiam ser consideradas livres. Então, teoricamente, de acordo com a interpretação feita na defesa sumária de Arminda, por ser filha e neta de pardas livres, seria nascida de ventre livre. A fim de provar as constatações da defesa, foi requerido ao coletor de rendas gerais da Vila da Encruzilhada que despachasse a matrícula da parda Arminda.

No referido documento, datado de 24 de setembro de 1873, Arminda aparece registrada sob o número dois mil quatrocentos e sessenta e sete na ordem da matrícula geral de cativos do município, tendo como senhor Feliciano Pereira Henriques. Nesse documento é feita uma descrição da parda que é apresentada da forma seguinte (APERS: 1883 - Civil e Crime. $\mathrm{N}^{\circ} .1714$, E. 122, M. 55.): ${ }^{7}$

nome do escravo $=$ Arminda,$=$ sexo feminino, $=$ cõr parda,$=$ idade - onze annos, $=$ estado solteira, = filha natural de Raphaela, escrava de Firmina Soares de Freitas, bõa aptidão para o trabalho, $=$ profissão serviço domestico, $=$ observação $=$ havida por herança; averbação = não tem.

Arminda, portanto, ao tempo da denúncia feita contra seu senhor através de seu curador, como é demonstrado no documento, já havia atingido a idade de vinte e um a vinte e dois anos. Tinha como ofício a prestação de serviços domésticos.

Após a apresentação da matrícula de Arminda, no dia 7 de abril de 1883, foi feito um auto de perguntas à Firmina Soares de Freitas. Firmina, em seu depoimento, declarou que combinara com Feliciano Pereira Henriques o batismo de Arminda como forra, sendo que a mesma não entraria na partilha feita em inventário por falecimento de Anna Soares, filha de Firmina e esposa de Feliciano. Declarou mais a interrogada dizendo que Arminda era, de fato, filha da escrava Rafaela e que apenas durante seu depoimento é que descobrira que a parda 
havia sido matriculada como cativa. Além disso, considerou que Henriques sabia da vinda de Rafaela, mãe de Arminda, do Estado Oriental do Uruguai.

Em sequência, o réu, Feliciano Pereira Henriques, prestou seu depoimento. O mesmo "disse ter quarenta e nove annos de idade, ser casado, criador natural e morador nesta freguesia, e que éra o proprio de que se trata n'esta causa" (APERS: 1883 - Civil e Crime. $\mathrm{N}^{\circ}$. 1714, E. 122, M. 55.). ${ }^{8}$ Também declarou que não contestava a estadia de Firmina, Maria e Rafaela no Estado Oriental, época em que era criança, e que já encontrara Rafaela, mãe de Arminda, em posse de Anna Soares, filha de Firmina, quando havia se unido à mesma em matrimônio.

Em um auto realizado com cinco testemunhas, todas afirmaram que Arminda era, de fato, filha de Rafaela e neta de Maria, confirmando também a ida de Firmina e sua escrava à República Oriental. Logo após, é reforçada a interpretação feita de acordo com as premissas da Lei de 07 de Novembro de 1831 de que Arminda seria livre por terem voltado do Estado Oriental sua mãe e avó.

Então, pelas provas apresentadas, foi deferida a sentença que declarava livres tanto a parda Arminda como também Maria e Rafaela. Dando sequência ao processo, teve início o julgamento de Feliciano Pereira Henriques.

Em um auto de testemunhas, feito com os depoimentos das mesmas cinco anteriores, todos concordaram com a ida de Firmina ao Estado Oriental do Uruguai. Além disso, foi revelado que Anna Soares, antes de casar-se com Feliciano Pereira Henriques, fora unida com Ernesto Vianna e que, por falecimento deste, fez um inventário em que constava a escrava Rafaela.

Após um interrogatório no qual Feliciano declarou que possuía provas que confirmavam sua inocência e que seu advogado as apresentaria no tempo correto, o advogado do réu, também curador de Arminda, João Baptista de Oliveira Brandão, apresenta a defesa sumária de Henriques. $\mathrm{O}$ auto afirmava que Feliciano se encontrava denunciado pelo crime de re-escravização contra a parda Arminda, "sendo esta livre $-1^{\circ}$ por haver de ventre livre nascido $-2^{\circ}$ por ter sido como livre baptisada" (APERS: 1883 - Civil e Crime. $\mathrm{N}^{\circ} .1714$, E. 122, M. 55.). ${ }^{9}$ Sobre estas acusações é dito que

(...) Quanto ao $1^{\circ}$ ponto - haver Arminda nascido de ventre livre - nenhuma responsabilidade cabe ao accusado; antes, se responsabilidade ha, recahe toda inteira em D. Firmina Soares de Freitas, que foi quem matriculou e manteve neste municipio como suas escravas - Maria e Rafaella - avó e mãe de Arminda - depois de regressarem do Estado Oriental para esta provincia, as quaes só forão declaradas

\footnotetext{
${ }^{8}$ APERS: 1883 .

${ }^{9}$ APERS: 1883 .
} 
livres pela mesma sentença que libertou Arminda, como se vê do respectivo traslado á fs. 15 e 16.

Quanto ao $2^{\circ}$ ponto - ter sido Arminda baptisada como livre - tambem d'ahi nenhuma responsabilidade vem ao accusado, em vista do que se passa a espender.

Foi afirmado ainda que Rafaela já constava no inventário feito por morte de Ernesto Vianna, então marido de Anna Soares, e que a mesma escrava se encontrava em posse de Anna quando Henriques veio a se casar com ela. Logo após, Rafaela concebeu Arminda. Quando Anna Soares faleceu, Henriques julgou que Arminda fosse também escrava, já que sua mãe constava como tal. Segundo a defesa, ambas entraram em partilha com Firmina Soares de Freitas, que acabou ficando com elas, mas trocou Arminda por um outro escravo pertencente a Feliciano. Após essa partilha, o réu teria, supostamente, matriculado Arminda como sua escrava.

$\mathrm{Na}$ mesma defesa, é contestado o depoimento de Firmina no que diz respeito ao batismo da parda Arminda como livre, com base em que

(...) em primeiro lugar, que D. Firmina Soares de Freitas não podia mandar baptisar como forra uma escrava que então não lhe pertencia: em segundo lugar, que, se esta realmente o houvesse feito, não viria depois a trocar Arminda como escrava: em terceiro lugar finalmente, que, se Arminda houvesse sido com effeito baptisada como forra, existiria o respectivo assento, recommendado sempre n'esses casos ao cuidado dos padrinhos, que o devem assignar (APERS: 1883 - Civil e Crime. $\mathrm{N}^{\circ}$. 1714, E. 122, M. 55.). ${ }^{10}$

Foi afirmado, então, que Arminda, de fato, nunca havia sido batizada. Este fato foi explicado da seguinte forma: "fazendo o accusado uma viagem demorada para fóra do municipio, deixou ordem a um seu irmão para mandal-a baptisar, o que este nunca fez, enganando entretanto ao accusado, a quem disse em seu regresso havel-o feito; e nessa crença viveo sempre o accusado.” (APERS: 1883 - Civil e Crime. №. 1714, E. 122, M. 55.). Com este argumento, o advogado Brandão solicitou o enquadramento de Henriques no artigo $3^{\circ}$ do Código Criminal do Império do Brasil, que afirma que "Não haverá criminoso ou delinquente sem má fé, isto é, sem conhecimento do mal e intenção de o praticar.” (BRASIL, 1830).

Como provas para sustentar a defesa, são apresentados: o inventário feito quando do falecimento de Ernesto Vianna, em que, de fato, consta a escrava Rafaela, no valor de 1:000\$000 (um conto de réis), e que a mesma foi repassada, em partilha, para sua viúva, Anna Soares ${ }^{11}$; e uma declaração afirmando a inexistência da certidão de batismo da parda Arminda na paróquia da Vila da Encruzilhada, assinada pelo escrivão interino Joaquim Antonio de Borba Netto.

\footnotetext{
${ }^{10}$ APERS: 1883.

${ }^{11}$ O inventário de Ernesto Antonio de Sá Vianna não se encontra nos livros de inventário do Arquivo Público do Estado do Rio Grande do Sul (APERS), mas sim em anexo no próprio processo-crime da parda Arminda (APERS: 1883 - Civil e Crime. N. 1714, E. 122, M. 55.).
} 
No final do processo, foi apresentada a sentença do juiz municipal Francisco de Farias Villas Boas (APERS: 1883 - Civil e Crime. N. 1714, E. 122, M. 55.).

Denuncia a Promotoria Publica a Feliciano Pereira Henrique, pelo crime previsto no art 179 do Cod. Crim. De ter; o mesmo reduzido pessoa livre á escravidão. Mas considerando que o reo apenas de conservar, como captiva, em seu poder a parda Arminda filha de Raphaela, não o fez com consciencia e por conseguinte sem má fé, pois quando se casou com Anna soares, hoje fallecida, filha de D. Firmina Soares de Freitas, e ja aquella viuva, possuia a referida parda Arminda, como escrava, e assim a trouce para o casal. E considerando que neste processo, e de sua prova existente, $o$ reo tem á seu favor á desposição do art $3^{\circ}$ do Cod. Crim. cuja doutrina é determinada pelo accordão de 20 de Abril de 1875 declarando os juizes formadores da culpa, a podem reconhecer.

Portanto, ao fim do processo, foi declarado que Feliciano Pereira Henriques cometeu o crime de re-escravização, mas sem má-fé, ou seja, sem conhecimento do enquadramento na legislação que tornava o cativeiro da parda Arminda ilegal.

Arminda, Rafaela e Maria foram libertadas do cativeiro em que se encontravam, tendo a seu favor a Lei Pátria de 7 de novembro de 1831. Feliciano Pereira Henriques foi liberado.

\section{A LEI DE 7 DE NOVEMBRO DE 1831}

O processo da parda Arminda é um caso complexo e cheio de reviravoltas. Contudo, o que o torna mais interessante se dá com o argumento utilizado para a liberdade de Arminda. De fato, a Lei de 07 de Novembro de 1831 previa que, pela interpretação utilizada, a mesma parda fosse livre. Porém, a aplicação direta dos preceitos da Lei ocorreu com Maria, sua avó, que havia cruzado a fronteira entre o Estado Oriental do Uruguai e o Brasil, junto com sua filha Rafaela. Sendo assim, a Lei de 1831 libertou três gerações de cativas em um único processo.

Várias vezes mencionada neste texto, a Lei Feijó, promulgada no dia 7 de novembro de 1831, visava acabar com o tráfico de escravos africanos, demonstrando, assim, à Coroa britânica - que fazia pressão para que o tráfico fosse abolido - que o Brasil estava se esforçando para dar fim ao comércio negreiro internacional. Contudo, essa legislação nunca foi efetivamente posta em prática, não sendo cumprida pelos envolvidos com o tráfico (GURGEL, 2004). Apenas a partir do final da década de 1850 e início da de 1860 foi que a Lei Feijó passou a ser interpretada para a libertação de escravos.

A Lei Feijó, teoricamente, atuava na libertação de cativos que haviam cruzado a fronteira, entrando no Brasil, após a data de promulgação da mesma. Em seu artigo $1^{\circ}$ diz (BRASIL, 1831) 


\begin{abstract}
Art. $1^{\circ}$ Todos os escravos, que entrarem no territorio ou portos do Brazil, vindos de fóra, ficam livres. Exceptuam-se:

$1^{\circ}$ Os escravos matriculados no serviço de embarcações pertencentes a paiz, onde a escravidão é permittida, emquanto empregados no serviço das mesmas embarcações.

$2^{\circ}$ Os que fugirem do territorio, ou embarcação estrangeira, os quaes serão entregues aos senhores que os reclamarem, e reexportados para fóra do Brazil.
\end{abstract}

Portanto, de acordo com os preceitos da Lei, todos os escravos que atravessassem a fronteira, entrando no Brasil, deveriam ser libertados. Sendo assim, Maria, por ter entrado em território do Império, vinda do Estado Oriental do Uruguai, devia ser livre. Contudo, apesar de, em teoria, estar em vigor, esta lei teve uma grande oposição, devido à importância dos escravos na economia brasileira. Segundo Keila Grinberg (2009)

O discurso político geral dos anos 1820 a 1840 reforçava a necessidade do braço africano para o desenvolvimento do país. Ao mesmo tempo, a escravidão tinha um papel importante na autoimagem do Brasil independente. A civilização brasileira, sociedade altamente hierarquizada, era baseada na escravidão africana e se via como dependente do trabalho africano. Pelo menos até os anos 1850, quando o tráfico atlântico de escravos foi proibido e o preço dos escravos subiu significativamente, ainda mais do que já vinha subindo desde a década de 1820, a posse de escravos era compartilhada largamente pela população livre, como já há algum tempo vêm demonstrando vários estudos sobre o tema.

O discurso político da época dizia que os escravos eram necessários, sendo que a civilização brasileira tinha a escravidão como uma de suas bases, sendo dela dependente. A posse e o tráfico de escravos permaneceram amplos até a década de 1850 (GRINBERG, 2009).

Nesse sentido, Chalhoub (2012) afirma que aproximadamente 750 mil negros foram contrabandeados para terras brasileiras até cerca de duas décadas após a promulgação da Lei Feijó, sendo ilegalmente escravizados, além de seus descendentes.

Com isso, é necessário entender de que forma a Lei Feijó foi utilizada - diga-se, de forma mais em conta, interpretada. Para compreender a aplicação da Lei e demonstrar a maneira como ela beneficiou os cativos que se enquadravam em seus preceitos, primeiramente é preciso analisar o contexto do início do século XIX no Brasil, levando em conta a influência gerada pela Grã-Bretanha contra o tráfico de escravos.

No decorrer do século XIX, medidas para a abolição do tráfico de escravos no Brasil foram tomadas não por questões humanitárias, mas por pressão estrangeira. No princípio deste século, a Grã-Bretanha tomava como dever interferir em assuntos de Portugal, do Brasil e de outras nações se isto viesse a encerrar o tráfico internacional de escravos. Essa pressão da Grã-Bretanha foi muito importante para a abolição do tráfico negreiro no Brasil. (CONRAD, 1978; PARRON, 2011). O primeiro passo para a abolição do tráfico negreiro transatlântico 
para o Brasil foi tomado em 1810. De acordo com Bethell (1976, p. 20), um autor clássico sobre o tema

\begin{abstract}
Em agosto de 1807, Napoleão mandara um ultimato a D. João, o príncipe regente de Portugal, governando em nome de sua enlouquecida mãe, Dona Maria I: deveria fechar os portos portugueses aos navios ingleses, trazendo assim Portugal para o Sistema Continental, com o objetivo de impedir o comércio britânico com a Europa, se não quisesse enfrentar as consequências de uma invasão francesa. Ameaçando, por um lado, destruir a esquadra portuguesa no Tejo e apoderar-se das colônias portuguesas se ele cedesse, e prometendo, por outro lado, renovar os já existentes compromissos britânicos de defender a Casa de Bragança e seus domínios contra ataques externos, se ele permanecesse firme, Lord Strangford pôde pressionar D. João a rejeitar o ultimato, e quando, em novembro, o General Junot marchou sobre Lisboa, a família real portuguesa e a Corte, escoltadas por quatro navios de guerra britânicos, procuraram refúgio do outro lado do Atlântico, no Brasil.
\end{abstract}

Assim se deu a vinda da família real portuguesa para o Brasil. Pelo auxílio prestado pela Grã-Bretanha, tanto na defesa de Portugal quanto na sua escolta para o Brasil, D. João, em 1808, abriu o comércio às nações amigas, com a Grã-Bretanha. Esta ficou em posição de estabelecer algumas exigências, estando, entre elas, a lenta abolição do tráfico de escravos por parte de Portugal.

Com isso, nos anos seguintes, foram estabelecidos tratados anglo-portugueses, visando uma gradual transição que levasse ao fim da escravidão. O primeiro, um Tratado de Aliança e Amizade, foi firmado em 1810, visando o início de uma gradual abolição do tráfico de escravos. Este acordo previa que o tráfico seria mantido apenas em territórios africanos pertencentes a Portugal ou sobre o qual tivesse pretensões que fossem legítimas. Após isto, no Congresso de Viena, realizado em 1815, a Grã-Bretanha conseguiu, através de outro tratado, dar fim ao tráfico de escravos ao norte do paralelo do Equador. Este segundo tratado gerou atritos entre os ingleses e os traficantes. Após, a convenção adicional de 28 de julho de 1817 reiterou e reforçou o tratado anterior (PARRON, 2011). A convenção previa o direito de vistorias, o aprisionamento de navios que traficavam ilegalmente acima do Equador, indenização por prisões indevidas, proibição de escravização em áreas territoriais de ambos os países e a criação de comissões mistas de julgamento anglo-portuguesas, estas situadas no Rio de Janeiro, em Londres e em Serra Leoa (RODRIGUES, 2000).

Finalmente, a independência brasileira, ocorrida em 1822, foi reconhecida internacionalmente em 1825, seguida de outro tratado, firmado em 13 de novembro de 1826 e ratificado pela Coroa inglesa em 13 de março de 1827. Este tratado previa o fim do tráfico de escravos brasileiro para três anos a partir da vigência do mesmo, mantendo as normas da Convenção Adicional de 1817 (RODRIGUES, 2000). 
Apesar de haver sido estabelecido o dito prazo, não foi abolido o tráfico até 1830, como era previsto. A Grã-Bretanha passou a pressionar o Brasil por medidas de combate ao tráfico. Então, a Regência mandou fazer cumprir o tratado com a Grã-Bretanha (de 1827), ou seja, apresentar um projeto de lei que proibisse a entrada de africanos escravizados no Brasil. O projeto mais aceito foi o de Felisberto Caldeira Brant, o Marquês de Barbacena, em parceria com o padre Diogo Antônio Feijó. Foi então promulgada, em 7 de novembro de 1831, a chamada Lei Feijó, devido ao grande apoio do mesmo padre para a aprovação da mesma (GURGEL, 2004). A Lei Feijó, contudo, apesar de ter sido utilizada após sua promulgação em alguns casos, deixou de ser aplicada, pois ia contra os interesses dos proprietários de escravos, que eram importantíssimos para a economia brasileira.

Chalhoub (2012) ressalta que nas duas décadas que se seguiram à promulgação da dita legislação, cerca de 750 mil negros foram contrabandeados clandestinamente para dentro das fronteiras do Império do Brasil, sendo estes mesmos mantidos em cativeiro ilegal. A principal atividade econômica que continuava a movimentar a máquina do escravismo brasileiro era a plantação de café, realizada nas regiões mais ao norte. Já na Província do Rio Grande de São Pedro do Sul, a força de trabalho cativa era empregada principalmente nas atividades pastoris das estâncias rio-grandenses, nas charqueadas e em atividades domésticas.

No caso específico da parda Arminda, em nenhum momento é feita alguma alusão de que a escrava Maria (avó de Arminda) tenha sido trazida após a data em que se fez válida a Lei Feijó. Contudo, na interpretação realizada pelo juiz responsável pelo caso, o artigo primeiro do referido instrumento legal, que ressalta que seria livre qualquer cativo que cruzasse a fronteira após a promulgação, entrando no país, foi considerado no devido contexto. Sendo assim, tendo saído do território nacional, adentrando no Estado Oriental do Uruguai, local onde Simão possuía bens e, entre 1839 e 1840, retornado ao Brasil, já se fazia cumprir os preceitos da legislação vigente, ou seja, declarava Maria legalmente livre por ter cruzado a fronteira com o vizinho país do Prata.

Porém, os efeitos da Lei Feijó só se fizeram sentir mais fortes no terceiro quartel do século XIX (GRINBERG, 2006). A partir do final da década de 1850 e início da de 60, alguns poucos juízes com tendências abolicionistas passaram a fazer uso da legislação para declararem livres escravos que haviam cruzado a fronteira. Os cativos, em processos judiciais, não possuíam voz própria, sendo defendidos por um curador. No caso da parda Arminda, este era o advogado João Baptista de Oliveira Brandão. 
Por ter sido criada para satisfazer aos preceitos dos tratados anglo-portugueses, mas não efetivamente utilizada, a Lei Feijó ganhou o nome popular "lei para inglês ver", pelo qual é conhecida atualmente.

A elite agrária brasileira, os fazendeiros na Província do Rio Grande de São Pedro do Sul, assim como vários políticos, posicionavam-se contra o fim do tráfico negreiro, pois este colocaria em xeque o modo de produção hegemônico do Império. Os escravos eram a grande mão-de-obra das lavouras e, no caso do Rio Grande do Sul, peões de fazenda, além de auxiliares domésticos. Também, a venda dos mesmos gerava um amplo lucro para os comerciantes negreiros e para os fazendeiros. Era, portanto, desejável que a entrada de mãode-obra cativa permanecesse legalizada, ou seja, que a Lei Feijó fosse revogada. Segundo Chalhoub (2012, p, 36)

Ilegal (...) desde março de 1830, o tráfico foi proibido por lei aprovada no Parlamento brasileiro em 7 de novembro de 1831. Não obstante a proibição legal, e após decréscimo temporário nas entradas de africanos durante a primeira metade da década de 1830, o comércio negreiro, então clandestino, assumiu proporções aterradoras nos anos seguintes, impulsionado pela demanda por trabalhadores para as fazendas de café, useiro e vezeiro no logro aos cruzeiros britânicos auxiliado pela conivência e corrupção de autoridades públicas e com o apoio de setores diversos da população.

No que concerne à interpretação da Lei, um dos principais fatores é a travessia de regiões fronteiriças. Como já foi dito, em seu artigo $1^{\circ}$, a Lei Feijó declara que "Todos os escravos, que entrarem no territorio ou portos do Brazil, vindos de fóra, ficam livres." (BRASIL, 1831). Sendo assim, a questão das fronteiras possui uma grande importância na utilização da lei. Isto se fez muito presente na Província de Rio Grande de São Pedro do Sul, em razão do frequente transito de escravos entre esta e os países do Prata. Segundo Flores (2007, p. 36):

\footnotetext{
A fronteira, acima de tudo, não pode ser considerada como uma linha divisória, mas como um espaço. $\mathrm{O}$ espaço deve ser compreendido como produto da ação humana, um locus onde atividades produtivas e relações sociais ocorrem. Nesse sentido, acredito que "a fronteira não é uma linha, mas um espaço que se define mais por seus atributos sócio-econômicos e o limite, como conceito, é essencialmente político".
}

Sendo assim, a fronteira não se figura como uma linha fixa, mas como um local onde forças políticas e socioeconômicas de ambos os lados atuam. No âmbito da escravidão, neste caso específico, a fronteira possuía um caráter libertador, além de manejado, sendo utilizada por escravos, muitas vezes propositalmente, como forma de adquirir a liberdade. 


\section{CONSIDERAÇÕES FINAIS}

Pode-se, portanto, concluir que a Lei de 7 de novembro de 1831, a Lei Feijó, foi, de fato, utilizada, não o sendo, contudo, da forma prevista de acordo com seus preceitos. Houve casos de uso imediatamente após sua promulgação, tendo, porém, sua real aplicação ocorrido apenas em meados do século XIX, para libertar escravos que haviam cruzado a fronteira após a data de promulgação. O tráfico de cativos continuou apesar da legislação, sendo abolido apenas em 1850. A Lei Feijó foi aplicada, principalmente, em casos judiciais, como o da parda Arminda, sua mãe Rafaela e sua avó Maria. Portanto, os escravos que haviam entrado no país após 1831 que, com a ajuda de seus curadores, entravam em ação para a sua libertação eram os beneficiados com a efetividade da Lei, que declarava ilegal o cativeiro dos mesmos de acordo com seu artigo $1^{\circ}$.

A Lei Feijó de 7 de novembro de 1831 teve uma grande importância para a libertação de escravos a partir da segunda metade do século XIX, apesar de seu fracasso em ser efetivamente aplicada para acabar com o tráfico. Vários cativos na província de Rio Grande de São Pedro do Sul que atravessaram a fronteira do Uruguai foram libertos devido à interpretação da Lei por alguns operadores da justiça.

Portanto, há de se ver a real importância da Lei Feijó para a libertação de escravos. Apesar de não cumprida efetivamente, teve um grande papel para o processo de construção do que ainda viria a ser o fim do tráfico negreiro transatlântico, ocorrido em 1850.

\section{REFERÊNCIAS}

ARQUIVO PÚBLICO DO ESTADO DO RIO GRANDE DO SUL - APERS: 1850 - Civil e Crime. Autos No 3, M. 1 E. 122.

ARQUIVO PÚBLICO DO ESTADO DO RIO GRANDE DO SUL - APERS: 1883 - Civil e Crime. $N^{\circ} .1714$, E. 122, M. 55.

BARROS, J. D’A. O Campo da História: Especialidades e Abordagens. Petrópolis: Vozes, 2013.

BETHELL, L. A abolição do tráfico de escravos no Brasil: a Grã-Bretanha, o Brasil e a Questão do Tráfico de Escravos, 1807-1869. Tradução de Vera Nunes Neves Pedroso. Rio de Janeiro: Expressão e Cultura; São Paulo: Editora da Universidade de São Paulo, 1976.

BRASIL. Lei de 16 de dezembro de 1830. Manda executar o Codigo Criminal. Coleção de Leis do Império do Brasil - 1830. Disponível em: <http://www.planalto.gov.br/ccivil_03/leis/LIM/LIM-16-12-1830.htm>. Acesso em: 01 set. 2016.

BRASIL: Lei de 7 de novembro de 1831. Declara livres todos os escravos vindos de fôra do Imperio, e impõe penas aos importadores dos mesmos escravos. Coleção de Leis do Império 
do Brasil - 1831, Página 182 Vol. 1 pt 1. Disponível em: <http://www2.camara.leg.br/legin/fed/lei_sn/1824-1899/lei-37659-7-novembro-1831-564776publicacaooriginal-88704-pl.html> Acesso em: 07 set. 2016.

CHALHOUB, S. A Força da Escravidão: Ilegalidade e Costume no Brasil Oitocentista. São Paulo: Companhia das Letras, 2012.

CONRAD, R. Os últimos anos da escravatura no Brasil. Tradução de Fernando de Castro Ferro. Rio de Janeiro: Civilização Brasileira, 1978.

FLORES, M. F. da C. T. Contrabando e Contrabandistas na Fronteira Oeste do Rio Grande do Sul - (1851 - 1864). 2007. 208 f. Dissertação (Programa de Pós Graduação em História Mestrado e Doutorado) - Instituto de Filosofia e Ciências Humanas, Universidade Federal do Rio Grande do Sul, Porto Alegre, 2007.

GRINBERG, K. Reescravização, direitos e justiças no Brasil do século XIX. In: LARA, S. H.; MENDONÇA, J. M. (Org.). Direitos e justiças no Brasil: ensaios de história social. Campinas: Editora da UNICAMP, 2006. p. 101-128.

GRINBERG, K. Escravidão e relações diplomáticas Brasil e Uruguai, século 19. In: ENCONTRO ESCRAVIDÃO E LIBERDADE NO BRASIL MERIDIONAL, 4., 2009, Curitiba. Anais... Disponível em: <http://www.escravidaoeliberdade.com.br/site/images/Textos4/keilagrinberg.pdf > Acesso em: 07 set. 2016.

GURGEL, A. E. A Lei de 7 de Novembro de 1831 e as ações cíveis de liberdade na Cidade de Valença (1870 a 1888). 2004. 79 f. Dissertação (Programa de Pós-Graduação em História Social) - Universidade Federal do Rio de Janeiro, Rio de Janeiro, 2004.

MATHEUS, M. S. Fronteiras da liberdade: escravidão, hierarquia social e alforria no extremo sul do Império do Brasil. São Leopoldo: Oikos; Editora Unisinos, 2012.

PARRON, T. A política da escravidão no Império do Brasil, 1826-1865. Rio de Janeiro: Civilização Brasileira, 2011.

RODRIGUES, J. O infame comércio: propostas e experiências no final do tráfico de africanos para o Brasil (1800-1850). Campinas: Editora da Unicamp/CECULT, 2000.

VOGT, O. P.; RADÜNZ, R. Condenados à força: a escravidão e os processos judiciais no Brasil. Metis - História e Cultura, Caxias do Sul, v. 11, n. 21, p. 209-228, jan./jun. 2012. Disponível em: <http://www.ucs.br/etc/revistas/index.php/metis/article/view/2076>. Acesso em: 24 set. 2016.

ZUBARAN, M. A. Escravidão e liberdade nas fronteiras do Rio Grande do Sul (1860-1880): O caso da Lei de 1831. Estudos Ibero-Americanos, Porto Alegre, v.32, n. 2, p. 119-132, dez. 2006.

Disponível

em: <http://revistaseletronicas.pucrs.br/ojs/index.php/iberoamericana/article/view/1359>. Acesso em: 01 set. 2016. DOI: http://dx.doi.org/10.15448/1980-864X.2006.2.1359. 
Como citar este documento: SCHNEIDER, Cícero Augusto Richter; RADÜNZ, Roberto; VOGT, Olgário Paulo. A aplicação da "Lei para Inglês Ver" de 1831 para a libertação de escravos no Rio Grande do Sul. Revista Jovens Pesquisadores, Santa Cruz do Sul, v. 7, n. 1, jan. 2017. ISSN 2237-048X. Disponível em: <https://online.unisc.br/seer/index.php/jovenspesquisadores/article/view/9322>. Acesso em: ... doi: http://dx.doi.org/10.17058/rjp.v7i1.9322. 